\title{
Temperature and strain rate effects on the mechanical properties of a polymer-bonded explosive
}

\author{
S.M. Walley ${ }^{\mathrm{a}}$, N.E. Taylor, and D.M. Williamson \\ SMF Fracture and Shock Physics Group, The Cavendish Laboratory, \\ J.J. Thomson Avenue, Cambridge CB3 0HE, UK
}

Received 28 July 2017

Published online 10 September 2018

\begin{abstract}
The aim of the research reported here was to investigate the strain rate and temperature sensitivity of Rowanex 1100 Type 1A, a polymer-bonded explosive (PBX). The stress supported by this PBX at high rates of deformation $\left(1750 \pm 225 \mathrm{~s}^{-1}\right)$ was found to be about an order of magnitude greater than that supported at low rates $\left(0.015 \mathrm{~s}^{-1}\right)$. Temperature was also found to have a large effect, with the strength of the material decreasing exponentially with temperature over the range studied $\left(-60\right.$ to $\left.+60{ }^{\circ} \mathrm{C}\right)$. The exponents for the decay of the PBX's strength with temperature at both low and high strain rates were the same within experimental error. So a temperature/strain rate shift factor could be determined and was found to be $31.2 \pm 2.4 \mathrm{~K} /$ decade of strain rate.
\end{abstract}

\section{Introduction}

During launch up a gun-barrel, the contents of an explosive shell are subjected to very high acceleration (ca. $200000 \mathrm{~m} \mathrm{~s}^{-2}$ ) [1]. This causes the phenomenon of "setback" in which the contents of the shell are subjected to a force towards the rear [2-9]. Due to the duration of the loading and the relatively low strains reached (due to the high bulk modulus of the explosive and the low volume fraction of voids), the strain rates are in the "intermediate" rather than high-rate regime [10]. Nevertheless the strain rates are higher than can easily be obtained in a conventional mechanical test machine. So in order to be able to simulate this phenomenon, it is important to understand the mechanical response of polymer-bonded explosives (PBXs) over a wide range of strain rates and temperatures $[1,10,11]$.

In recent years, a number of experimental studies have been performed to obtain such mechanical data e.g. [12-24]. The main conclusions of such research were: (i) the strain rate and temperature response are generally governed by the properties of the polymer binder $[15,16]$; (ii) the absolute value of the stress supported for a given strain rate and temperature is governed by the size of the explosive crystals $[12,14]$. Williamson et al. quantified the relationship between strain rate and temperature for

a e-mail: smw14@cam.ac.uk 


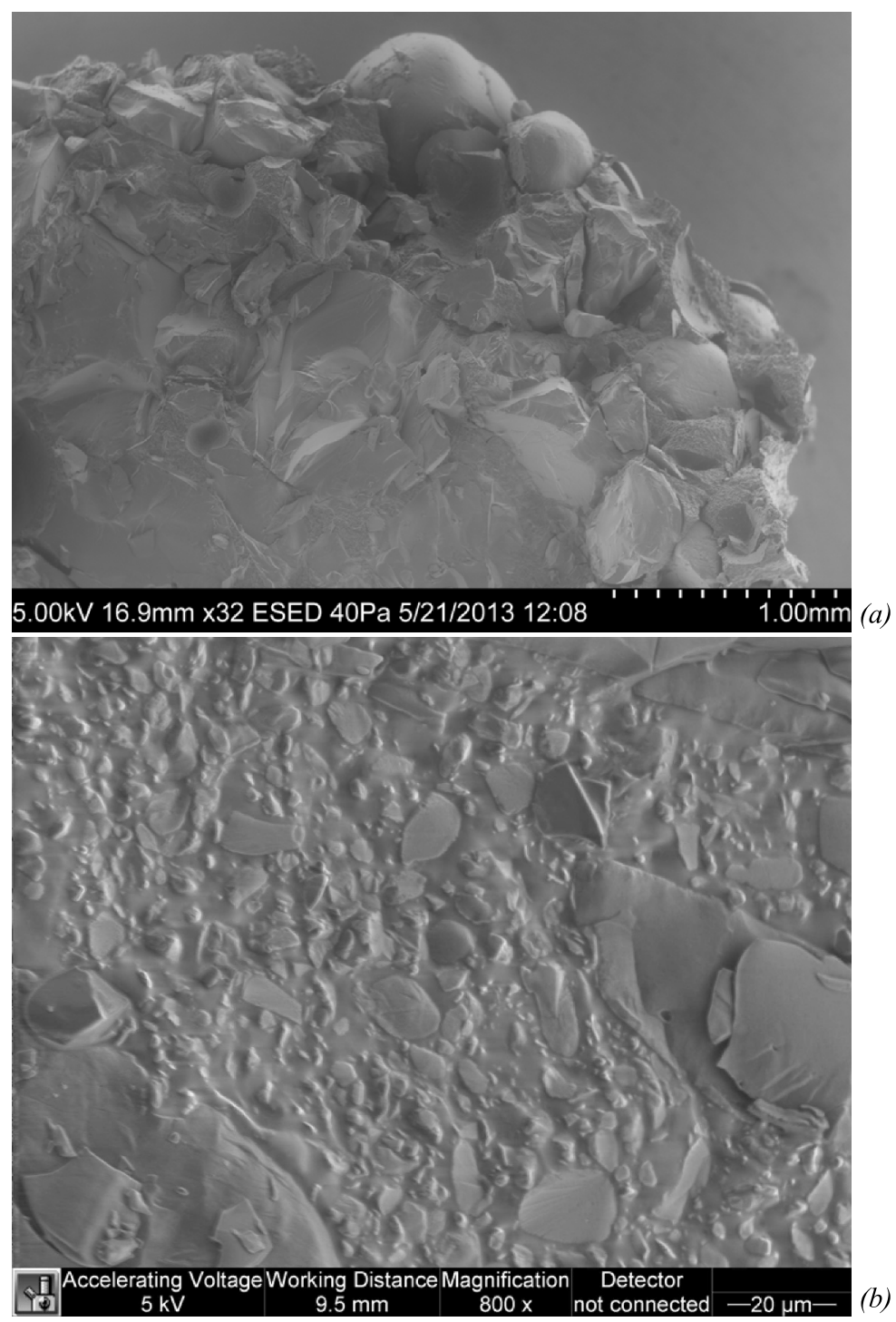

Fig. 1. (a) Low magnification ESEM (Environmental Scanning Electron Microscope) image of a cryogenically fractured surface of the PBX Rowanex 1100 Type 1A. (b) High magnification ESEM image of the PBX Rowanex 1100 Type 1A.

a particular PBX through a very detailed study in both monotonic and oscillatory loading [15].

The research reported in the present paper was performed on Rowanex 1100 Type 1A, a PBX loaded to $87 \%$ by volume with a bimodal particle size distribution of cyclotrimethylene-trinitramine (RDX) bound together with hydroxyl-terminated polybutadiene (HTPB). Environmental Scanning Electron Microscope (ESEM) images are presented in Figure 1 to show the microstructure. Figure 1a shows that the large RDX crystals are of the order of $1 \mathrm{~mm}$ in size. Figure $1 \mathrm{~b}$ shows that the binder in-between the large crystals is filled with small RDX crystals ranging in size from microns to tens of microns. 
Table 1. Properties of the magnesium AZM alloy bars used in our compression SHPB.

\begin{tabular}{ll}
\hline Bar diameter & $12.73 \mathrm{~mm}$ \\
Bar length & $0.5 \mathrm{~m}$ \\
Bar density & $1797 \mathrm{~kg} \mathrm{~m}^{-3}$ \\
Dynamic Young's modulus & $43.5 \mathrm{GPa}$ \\
Bar elastic wave speed & $4920 \mathrm{~m} \mathrm{~s}^{-1}$ \\
Bar material impedance & $8856000 \mathrm{~kg} \mathrm{~m}^{-2} \mathrm{~s}^{-1}$ \\
\hline
\end{tabular}

\section{Experimental method}

Cast PBX specimens were provided as discs with nominal dimensions $5 \mathrm{~mm}$ thickness and $10 \mathrm{~mm}$ diameter (i.e. a height/diameter ratio of 0.5 ). The actual dimensions of each specimen were measured using a micrometer. These discs were loaded axially in an Instron (model 5566) and a magnesium AZM alloy split Hopkinson pressure bar (SHPB). The Instron was used to obtain low-rate (ca. $0.015 \mathrm{~s}^{-1}$ ) and the SHPB was used to obtain high-rate (ca. $2000 \mathrm{~s}^{-1}$ ) compressive stress-strain data. In both cases, experiments were performed at temperatures between -60 and $+60{ }^{\circ} \mathrm{C}$.

A magnesium alloy SHPB was used in this study because magnesium has the lowest mechanical impedance of any commonly available metal $[25,26]$. A low impedance minimises the "ring-up" time for the low strength (few MPa) PBX specimens while maintaining the simplicity of elastic analysis [14]. Viscoelastic polymer bars have been developed and analysed by a number of research groups [27-39], but so far these have not been used for obtaining data at non-ambient temperatures as the analysis is complicated [40]. Metal tubes made from aluminium or magnesium alloys also have mechanical impedances comparable to polymers, but in order to use a tube as the output bar the load has to be transferred from the specimen to the tube via an endcap [41], which is mechanically more complex a simple rod. The relevant properties of our magnesium alloy SHPB system are presented in Table 1.

Environmental chambers were used for both the Instron and SHPB in order to obtain data at non-ambient temperatures. The temperature of the anvil (or bar end) was monitored using a Type K (chromel/alumel) thermocouple. Cooling of the chamber was achieved by a flow of dry nitrogen gas that had passed through a copper coil immersed in liquid nitrogen. Heating was achieved by blowing hot air into the chamber from a "heat-gun". As PBXs have a low thermal conductivity $[42,43]$ $\left(0.29 \pm 0.02 \mathrm{Wm}^{-1} \mathrm{~K}^{-1}\right.$ for the PBX studied here), the temperature of the enclosure was held at the target value for around five minutes to ensure that the specimen had thermally equilibrated with its environment (and hence also the thermocouple). Petroleum jelly was used as a lubricant at both strain rates as this has been found to give almost perfect lubrication for polymer discs loaded in compression [44-46].

The outputs of both test machines are the force the specimen supports as a function of time, $F(t)$, and the displacements of the specimen ends as a function of time. These can be converted to true stress $\sigma(t)$ and true strain $\varepsilon(t)$ using

$$
\sigma(t)=F(t) / A(t)
$$

where $A(t)$ is the cross-sectional area of the specimen at time $t$, and

$$
\varepsilon(t)=\ln \left(l_{0} / l(t)\right),
$$

where $l_{0}$ is the original specimen thickness, and $l(t)$ is the specimen thickness at time $t$. $A(t)$ is computed assuming the volume of the specimen remains constant i.e. $A_{0} l_{0}=A(t) l(t)$ where $A_{0}$ is the original cross-sectional area. 

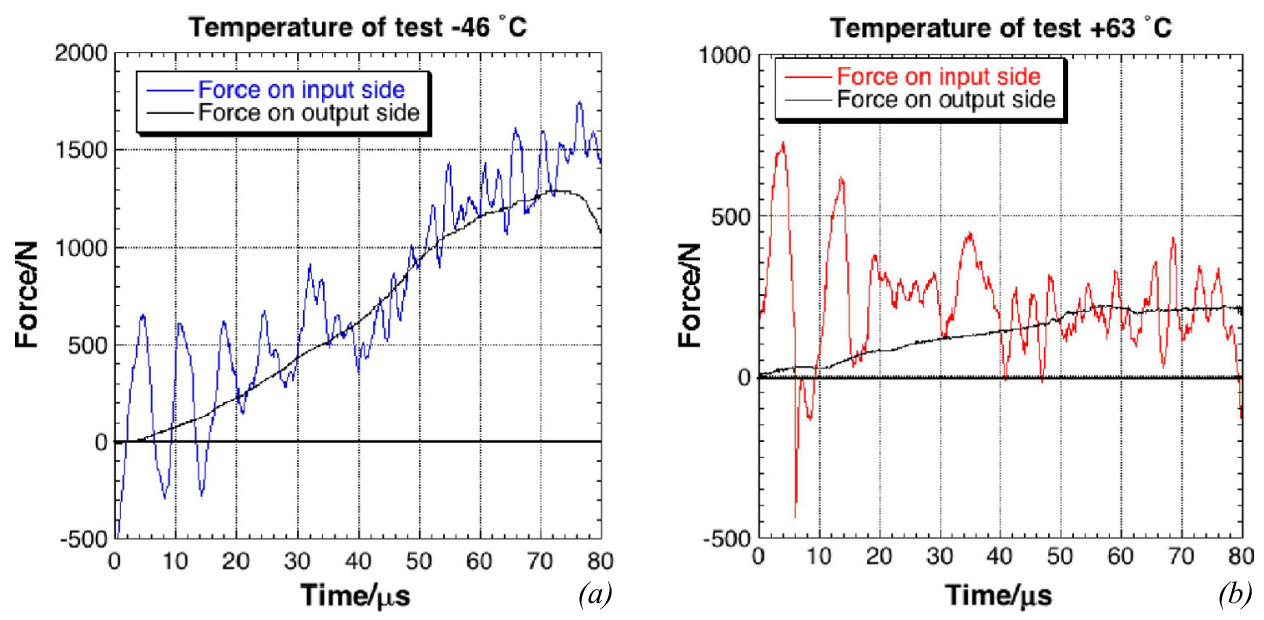

Fig. 2. Comparison of the forces on the input and output sides of PBX specimens deformed in our magnesium SHPB at (a) $-46^{\circ} \mathrm{C}$ and (b) $+63^{\circ} \mathrm{C}$.

As PBXs are low modulus materials [14], their elastic wave speed is small. So a check was made as to whether the specimens reached force equilibrium within the duration of the test (ca. $80 \mu \mathrm{s})$. The check consisted of calculating the forces on the input and output ends of specimens held at a low $\left(-46{ }^{\circ} \mathrm{C}\right)$ and a high $\left(+63^{\circ} \mathrm{C}\right)$ temperature making use of the so-called 1 -wave and 2-wave analysis [47]. The result of this check is shown in Figure 2. It can be seen that the colder (and hence stiffer) specimen reached force equilibrium more quickly than the one that was warmer.

Another assumption behind equations (1) and (2) is that the disc does not "barrel" i.e. the deformation is uniform and homogeneous. A check was made of these assumptions using high-speed photography. The first study we know of into whether a polymer deforms plastically at constant volume was performed for polyethylene in both rolling and tension by Carmichael [48]. The measured behaviour was complex (see Fig. 3), but for both modes of deformation studied the maximum volume change was less than $1 \%$ for engineering strains of up to $70 \%$.

More recent studies of this issue were performed over a number of years by G'Sell and co-workers [49-51]. Addiego et al. [51] investigated how the volumetric strain (defined as $\varepsilon_{v}=\varepsilon_{11}+\varepsilon_{22}+\varepsilon_{33}$ ) varied with the true axial strain $\varepsilon_{33}$ within the neck formed during the tensile deformation of high density polyethylene. They used two techniques: (i) the VidéoTraction system developed by G'Sell and co-workers [50,52] and (ii) wide-angle X-ray scattering (WAXS). They found that there was initially a very small dilatation that they identified with the elastic Poisson's ratio effect followed by a much larger dilatation due to damage associated with the growth of voids. An additional source of dilatancy can arise in highly-filled PBXs as they are granular materials in which the particles are bonded together using a polymer as an adhesive (or binder). And it is well-known that dense sands with particle shapes similar to PBXs can dilate during deformation [53]. So for these two reasons we performed an optical check on whether volume was conserved during dynamic deformation of the PBX specimens.

In our SHPB studies, we used a high-speed camera (Invisible Vision UHSi 12/24) to record the deformation. The interframe time was set to $7 \mu \mathrm{s}$ and the exposure time to $0.5 \mu \mathrm{s}$. The camera is sufficiently light-sensitive that the experiments could be back-lit using a bright continuous light-source. The camera was triggered using 


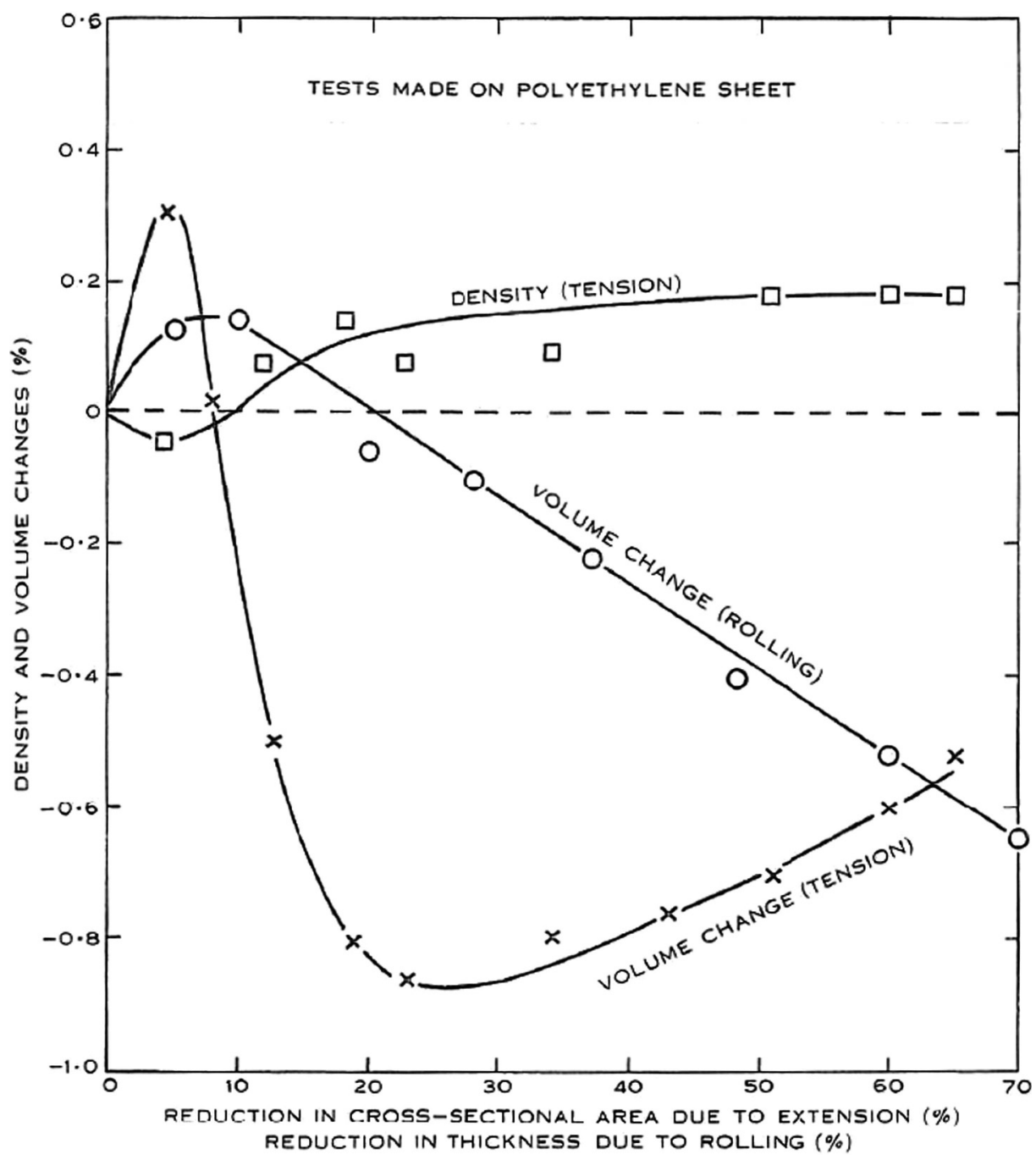

Fig. 3. Plots of percentage density and volume changes for polyethylene as functions of percentage reduction in cross-sectional area due to extension and percentage reduction in thickness due to rolling. From [48].

the rising edge of the voltage pulse output from the input bar's strain gauge bridge. A $40 \mu$ s delay was included since the gauge was $0.25 \mathrm{~m}$ from the end of the bar.

Figure 4 shows two frames from the beginning and the end of a high-speed sequence, for a test in which the specimen deformed as a right circular disc during loading. The bars and specimen are back-illuminated. They therefore appear as black silhouettes in the high-speed photographic sequences.

Using the diameter of the Hopkinson bars as a distance scale, the thickness and diameter of the specimen was measured and plotted as a function of time (Fig. 5). From these measurements the volume of the specimen can be calculated (Fig. 6). It can be seen that for this particular test, the assumption that PBX specimens deform at constant volume was valid for the duration of the experiment (ca. $80 \mu \mathrm{s}$ ), indicating that the assumptions made during the analysis of the data that resulted in the stress-strain graph presented in Figure 7 were reasonable. 

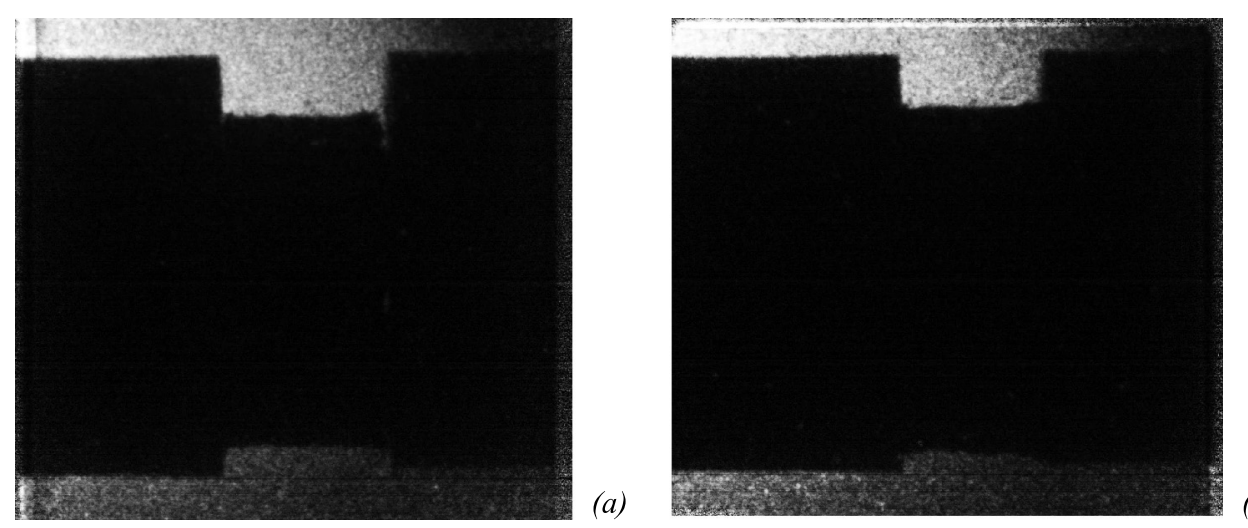

(b)

Fig. 4. Selected frames from the high-speed photographic sequence of the high strain rate deformation of a disc of the PBX Rowanex 1100 Type 1A. Times from the moment of trigger: (a) $0 \mu \mathrm{s}$ and (b) $77 \mu \mathrm{s}$. The diameter of the Hopkinson bars is $12.74 \mathrm{~mm}$. The input bar is to the left of the photograph and was moving to the right at $11.1 \mathrm{~m} \mathrm{~s}^{-1}$.

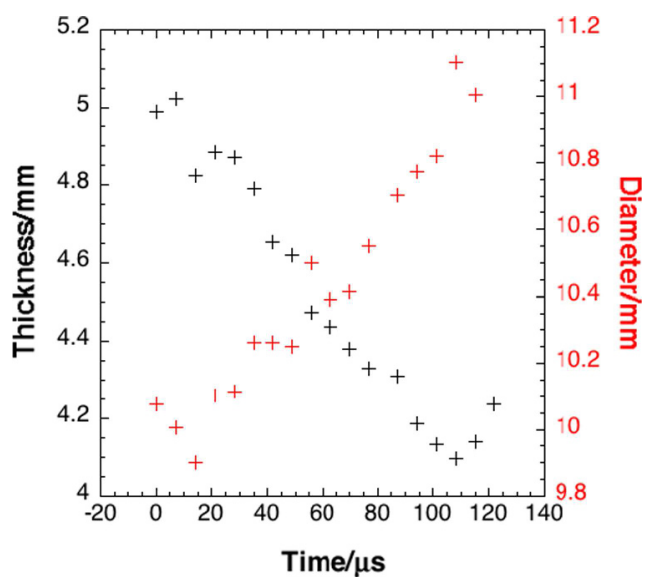

Fig. 5. Plots of the thickness and diameter versus time of the high-speed photographic sequence represented in Figure 4.

Not all the specimens that we tested deformed as right circular cylinders. The most usual departure from this ideal was for the diameter of the end in contact with the output bar to increase more than the end in contact with the input bar (see Fig. 8).

Specimens fabricated with a different (less complete) state of cure yielded at about half the strain. Thus during the period of loading they underwent a longer period of deformation at constant stress (compare Fig. 9 with Fig. 7). They were also found to increase slightly in volume during high rate deformation (see Fig. 10). It is not known whether this is due to the polymer or the RDX component of the PBX.

As the anvils used in the Instron have a diameter of $17 \mathrm{~mm}$, the maximum true strain achievable in this apparatus was ca. 1.1. For similar reasons, the maximum strain achievable in our $12.7 \mathrm{~mm}$ diameter SHPB was ca. 0.5. At strains greater than these, a specimen would have a diameter greater than the anvils (or rods) and hence no longer be in a state of uniform one-dimensional stress. In practice the loading time of the SHPB (ca. $80 \mu \mathrm{s}$ ) resulted in strains less than 0.5 being reached before unloading began. 


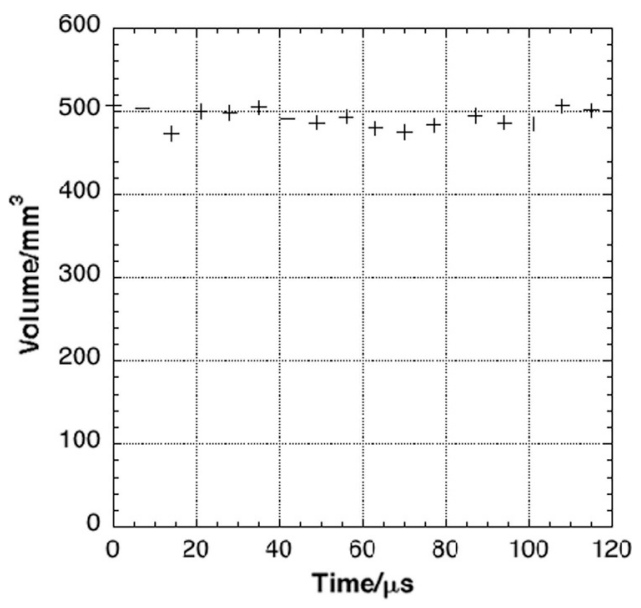

Fig. 6. Plot of the specimen volume versus time (data obtained from the high-speed photographic sequence shown in Fig. 4). The standard deviation of the data from a constant volume of $492.5 \mathrm{~mm}^{3}$ was $11 \mathrm{~mm}^{3}$.

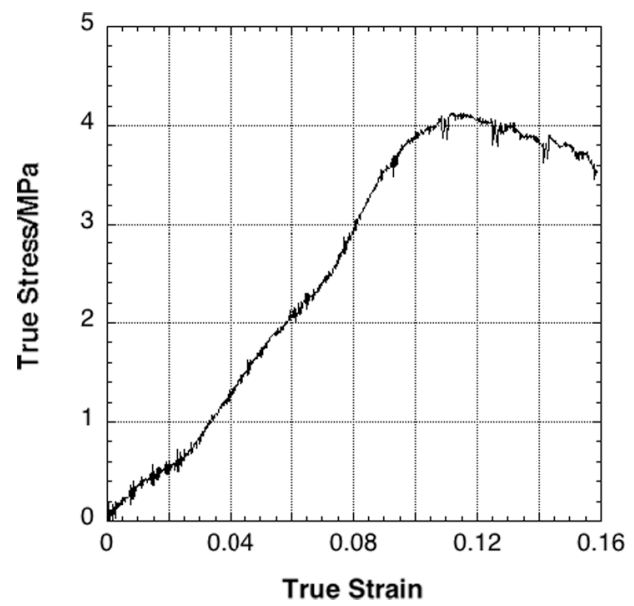

Fig. 7. True stress-true strain plot for a specimen of the PBX Rowanex 1100 Type 1A whose deformation was recorded using high-speed photography (see Fig. 4).

\section{Results}

True stress-true strain plots for the low strain rate compression of the PBX are presented in Figure 11, for a number of different temperatures. For clarity, the low and high temperature data have been plotted separately. The stress-strain curves exhibit a classic elastomer response with a load drop for strains greater than ca. 0.1, followed by a stress minimum at a strain of ca. 0.4. For strains greater than 0.4 , the PBX strain-hardens rapidly. Some specimens that were deformed at low temperatures fractured, resulting in sudden drops in the stress supported.

True stress-true strain plots for the high rate compression of the PBX at a number of different temperatures are presented in Figure 12. Unlike in low rate testing, there is a limit to the strain reached (ca. 0.15) set by the elastic wave double transit time $(80 \mu \mathrm{s})$ in the SHPB's striker bar. Thus there exists the possibility that the high rate stress-strain curves may have the same shape as those obtained at low rates if longer 

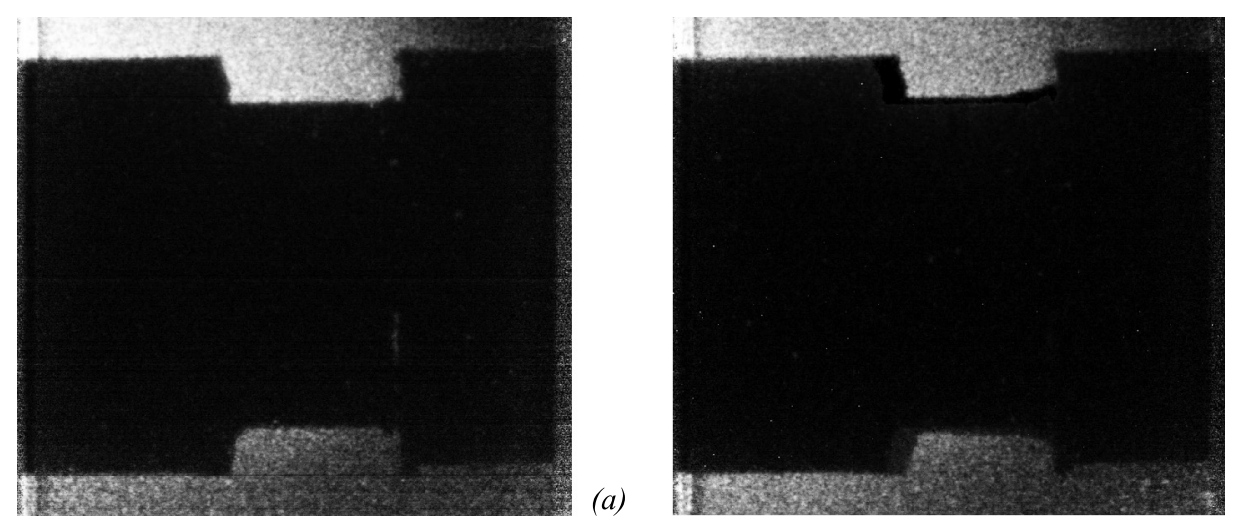

(b)

Fig. 8. Selected frames from the high-speed photographic sequence of the high strain rate deformation of a disc of the PBX Rowanex 1100 Type 1A. Times from the moment of trigger: (a) $0 \mu \mathrm{s} \mathrm{(b)} 87 \mu \mathrm{s}$. The diameter of the Hopkinson bars is $12.74 \mathrm{~mm}$. The input bar is to the left of the photograph and was moving to the right at $9.1 \mathrm{~m} \mathrm{~s}^{-1}$. The diameter of the specimen in contact with the output bar can be seen to increase more than the end in contact with the input bar.

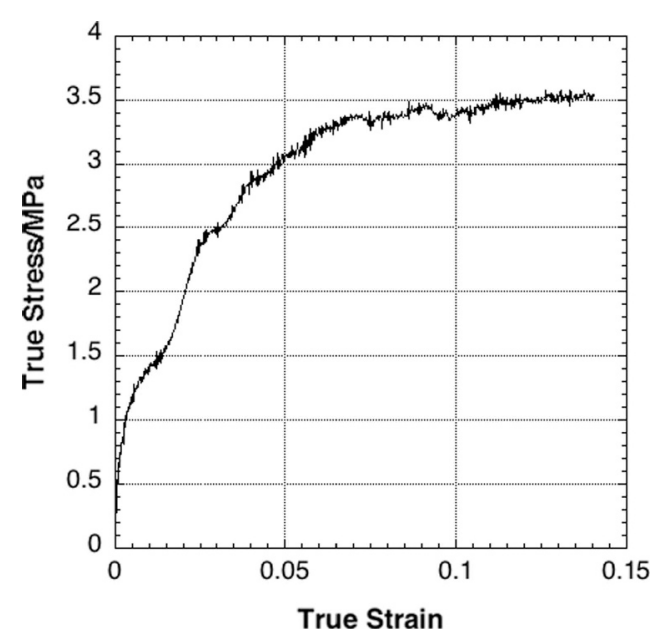

Fig. 9. True stress-true strain plot for a Rowanex 1100 Type 1A PBX sample fabricated using an alternative less complete curing method.

loading times had been applied $[22,54]$. However, a recent study by one of us has shown that the time taken for the stress to relax to half its maximum value for a polymer-bonded propellant tested in an SHPB was about $40 \mu \mathrm{s}$ [55]. As this is around half the loading time, it is likely that the shapes of the high rate stress-strain curves will be different to those obtained at low strain rates.

We believe the large variability in the data obtained at the lowest temperature studied $\left(-46^{\circ} \mathrm{C}\right)$ was due to the PBX's polymer binder beginning to undergo its glass transition [14]. Glass transitions produce large changes in the mechanical properties of polymers [56], so small variations in specimen composition or experimental conditions will have large effects.

Glass transitions occur over a temperature range rather than at a well-defined temperature [56,57]. The glass transition of the HTPB binder for this particular PBX determined using an oscillatory technique (differential mechanical thermal analysis, 


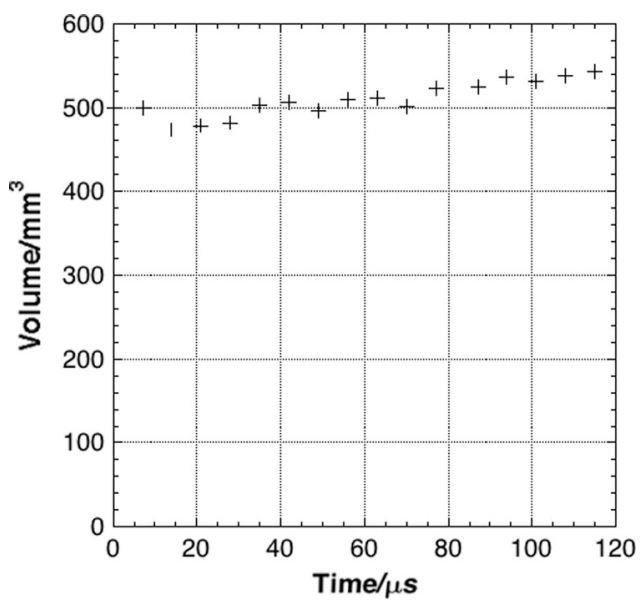

Fig. 10. Plot of the specimen volume versus time for the experiment whose stress-strain curve is shown in Figure 9. This specimen increased in volume from 480 to $540 \mathrm{~mm}^{3}$ during the test. The standard deviation in the data from a linear fit was $22 \mathrm{~mm}^{3}$.

DMTA) lies in the temperature range $-70^{\circ} \mathrm{C}$ to $-90^{\circ} \mathrm{C}$. However, a recent study has shown that the glass transition of a polymer bonded sugar (a PBX simulant) occurs over a higher temperature range [22]. And the temperature ranges for glass transitions have been found to be shifted to higher temperatures under monotonic dynamic loading conditions both for PBXs [15] and for polymers [58]. These authors reported rate-temperature shift factors for these materials.

In 1955 Williams, Landel and Ferry published a famous paper on the physics that gives rise to time-temperature superposition (and hence the existence of ratetemperature shift factors) [59]. A more extended discussion of their ideas may be found in reference [60]. However, an older theory of glass viscosity due to Vogel [61], Fulcher [62] and Tamman [63] is at present providing more physical insight in the modelling and simulation of polymers $[64,65]$.

In order to quantify the effect of temperature on the stress-strain response at the two strain rates studied, the low-strain stress maxima were obtained from the low strain rate curves. For the high strain rate curves, the flow stresses were used. Data recently obtained by Kendall and Siviour [22] give us confidence that this is a valid procedure.

For each temperature and strain rate the mean value and standard deviation were calculated (see Tabs. 2 and 3). This data is also plotted in Figure 13. The best fit to both sets of data is provided by exponential functions. Plotting the data in log-linear form (Fig. 14) gave a temperature/strain rate shift factor of $30.5 \pm 1 \mathrm{~K} /$ decade of strain rate.

However, an implicit assumption lies behind this straightforward analysis of the data, namely that the yield stress of the PBX tends to zero as the temperature tends to infinity. As there is no a priori reason for this assumption to be true, it needed to be investigated. In order to do this, an analysis was performed on the data using the Nelder-Mead nonlinear unconstrained optimization algorithm [66,67]. In what follows, the subscript $H$ on any variable indicates high rate and $L$ indicates low rate.

If the PBX under investigation has mechanical properties for which a change in temperature is equivalent to a change in strain rate, once the low rate strength data, for example, have been shifted to a temperature $T_{\text {test }}+T_{\text {tsf }}$ (where $T_{\text {test }}$ at which the experiments were performed and $T_{\text {tsf }}$ is the temperature shift factor) then the 

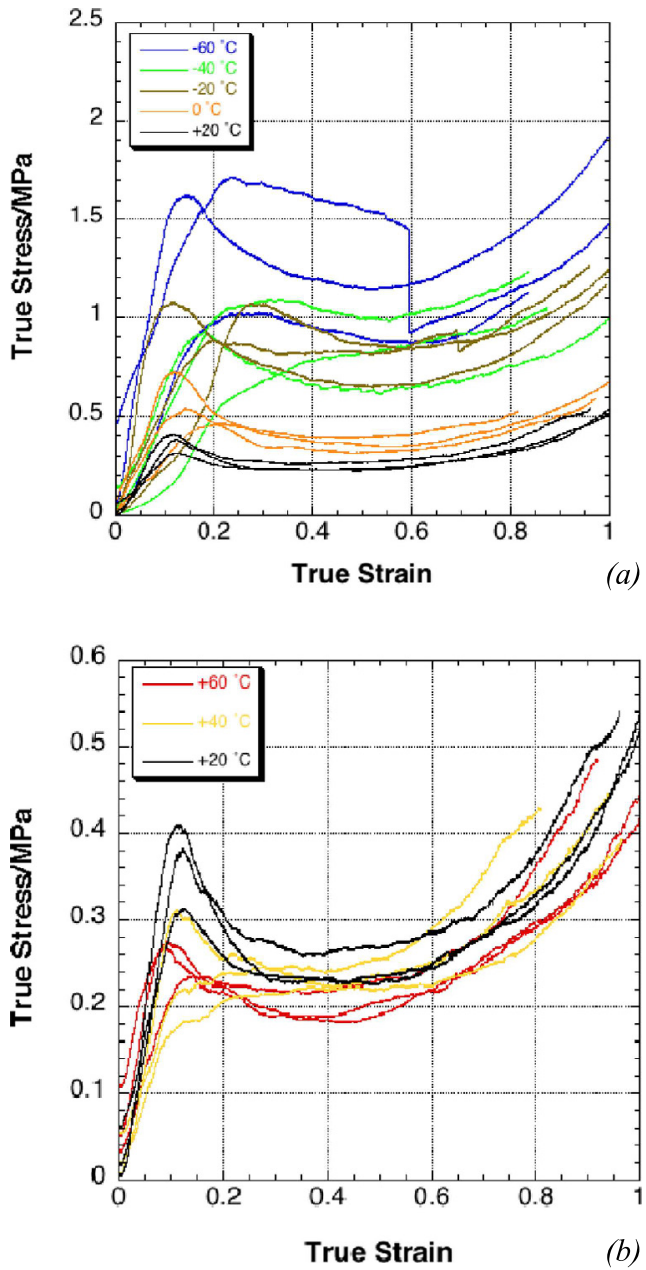

Fig. 11. True stress-true strain curves for the PBX Rowanex 1100 Type 1A obtained using an Instron at (a) room temperature and at a number of sub-ambient temperatures, (b) room temperature and at a number of above-ambient temperatures. Nominal strain rate $0.015 \mathrm{~s}^{-1}$. The drops in stress for one of the $-60{ }^{\circ} \mathrm{C}$ and one of the $-20{ }^{\circ} \mathrm{C}$ tests were due to failure of the specimens.

Table 2. Stress/MPa supported at the low strain, stress maximum of the stress-strain curves presented in Figure 11 for the PBX Rowanex 1100 Type 1A at seven different temperatures, for a nominal strain rate of $0.015 \mathrm{~s}^{-1}$.

\begin{tabular}{ll}
\hline Temperature $/{ }^{\circ} \mathrm{C}$ & True stress $/ \mathrm{MPa}$ \\
\hline-60 & $1.45 \pm 0.4$ \\
-40 & $0.93 \pm 0.16$ \\
-20 & $1.0 \pm 0.1$ \\
0 & $0.57 \pm 0.14$ \\
+20 & $0.36 \pm 0.05$ \\
+40 & $0.22 \pm 0.09$ \\
+60 & $0.23 \pm 0.07$ \\
\hline
\end{tabular}




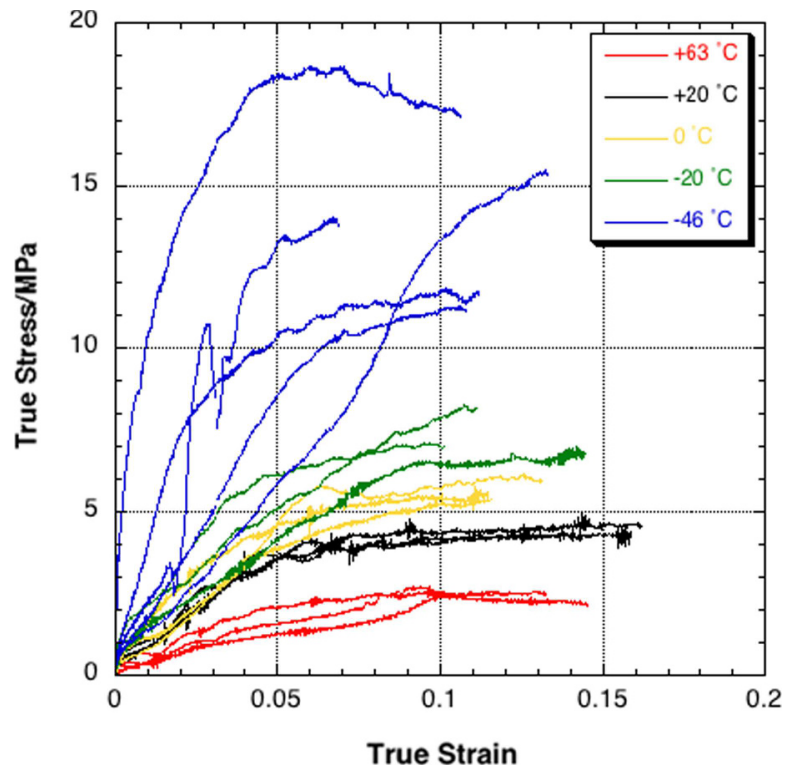

Fig. 12. True stress-true strain curves for fully cured PBX Rowanex 1100 Type 1A, obtained using an SHPB at a number of different temperatures. Nominal strain rate $2000 \mathrm{~s}^{-1}$ (mean strain rate for the 14 tests $1750 \pm 225 \mathrm{~s}^{-1}$ ).

Table 3. High strain rate flow stress/MPa for the PBX Rowanex 1100 Type 1A obtained at five different temperatures in our SHPB at strain rates of $1750 \pm 225 \mathrm{~s}^{-1}$ (data taken from stress-strain curves presented in Fig. 12).

\begin{tabular}{ll}
\hline Temperature $/{ }^{\circ} \mathrm{C}$ & True stress $/ \mathrm{MPa}$ \\
\hline-46 & $14 \pm 3$ \\
-20 & $7.2 \pm 0.8$ \\
0 & $5.6 \pm 0.4$ \\
+20 & $4.3 \pm 0.15$ \\
+63 & $2.5 \pm 0.2$ \\
\hline
\end{tabular}

exponential functions describing both datasets can be written as:

$$
\begin{gathered}
\sigma_{H}=A \exp \left(-\frac{T}{\lambda}\right)+\sigma_{\infty}, \\
\sigma_{L}=A \exp \left(-\frac{T+T_{\mathrm{tsf}}}{\lambda}\right)+\sigma_{\infty} .
\end{gathered}
$$

The most likely values for $A, l, \sigma_{\infty}$ and $T_{\text {tsf }}$ that are consistent with the data may now be found. As the algorithm used optimizes the sum of the squared residuals weighted by the reciprocal of the squared uncertainty, a data point with a large error bar will have less of an influence on the curve fit than a data point with a small error bar, as may be seen in Figure 15. The most important of the four parameters is $T_{\text {tsf }}$ which was calculated to $158 \pm 12 \mathrm{~K}$ giving a temperature/strain rate shift factor of $31.2 \pm 2.4 \mathrm{~K} /$ decade of strain rate. The graph shown in Figure 15 was arrived at by applying a positive temperature shift of $158 \mathrm{~K}$ to the low strain rate data and 


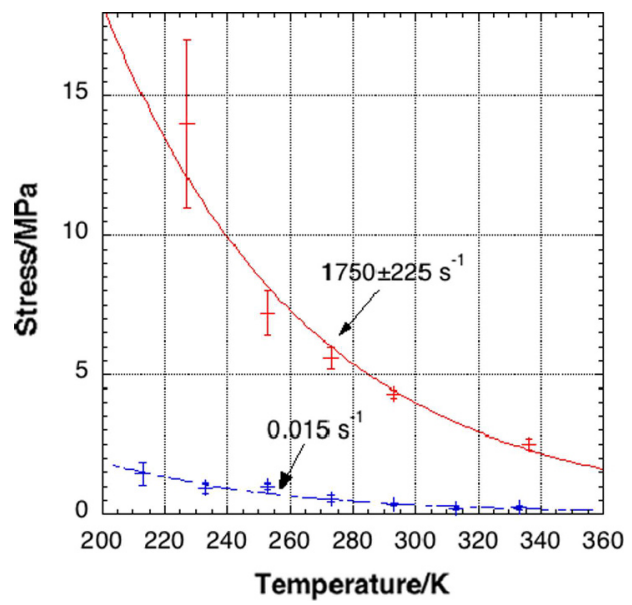

Fig. 13. Plot of flow stress (for high rate deformation) and maximum yield stress (for low rate deformation) as a function of temperature for the PBX Rowanex 1100 Type 1A. The stress-strain curves from which this data was extracted are presented in Figures 11 and 12. Exponential functions gave the best fit to both sets of data. The exponent for the low rate data was $-0.018 \pm 0.003 \mathrm{~K}^{-1}$. The exponent for the high rate data (mean strain rate calculated from 14 tests) was $-0.0135 \pm 0.0010 \mathrm{~K}^{-1}$.

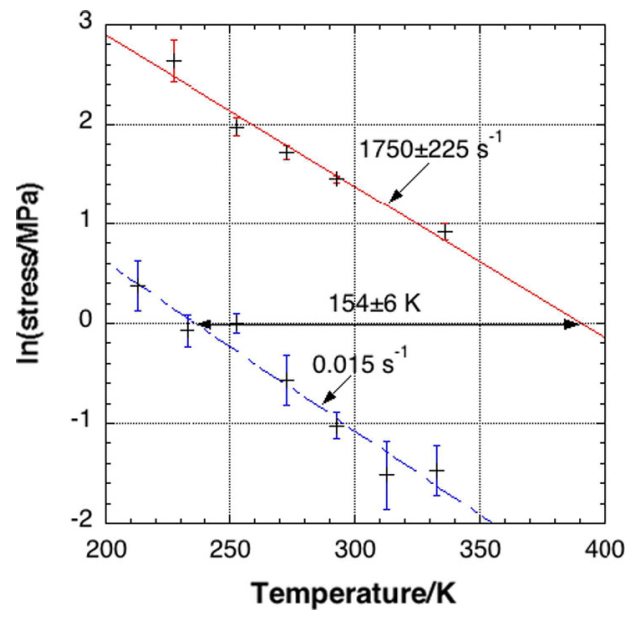

Fig. 14. Plot of the natural logarithms of the stresses shown in Figure 13 as a function of temperature for the PBX Rowanex 1100 Type 1A. The error quoted above for the temperature shift factor was calculated from measurements obtained at three different values of $\ln ($ stress $/ \mathrm{MPa})$.

replotting the data presented in Tables 2 and 3 . Note that $\sigma_{\infty}(=-0.19 \pm 0.14 \mathrm{MPa})$ is close to zero.

\section{Recommendations for future work}

As can be seen from Figure 15, the temperature-shifted data do not overlap. So a future study should perform tests over a wider range of rate and temperature to ensure that the datasets obtained overlap after temperature- or rate-shifting. This 


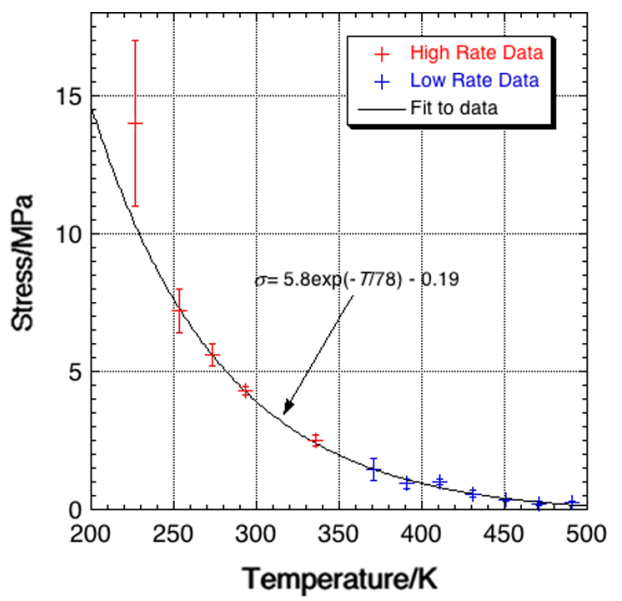

Fig. 15. Plot of flow stress (for a strain rate of $1750 \mathrm{~s}^{-1}$ ) and maximum yield stress (for a strain rate of $0.015 \mathrm{~s}^{-1}$ ) as a function of temperature for the PBX Rowanex 1100 Type 1A. The low strain rate data have been shifted to a temperature of $T_{\text {test }}+158 \mathrm{~K}$. The curve was fitted to the data using a nonlinear unconstrained optimization algorithm.

could be achieved either by conducting low rate tests at lower temperatures than was done in the study reported here or by obtaining mechanical data at intermediate strain rates. A more accurate value for $\sigma_{\infty}$ could be determined by obtaining more data at low strain rates and/or higher temperatures.

\section{Conclusions}

The stress supported by the PBX Rowanex 1100 Type 1A at high rates of deformation $\left(1750 \pm 225 \mathrm{~s}^{-1}\right)$ was found to be about an order of magnitude greater than that supported at low rates $\left(0.015 \mathrm{~s}^{-1}\right)$. Temperature also had a large effect, with the strength of the PBX decreasing exponentially with temperature over the range studied $\left(-60\right.$ to $\left.+60^{\circ} \mathrm{C}\right)$. As the exponents at both low and high strain rates were the same within experimental error, a temperature/strain rate shift factor could be determined $(31.2 \pm 2.4 \mathrm{~K} /$ decade of strain rate).

We thank BAe Systems, Glascoed, UK for funding this research and providing specimens of the PBX. Ron Hollands of BAe Systems is thanked for his interest in the project. Peter Gould is thanked for insights into the physical meaning of temperature and rate effects in polymers. Lewis Lea is thanked for help with the analysis of force equilibrium in results from specimens tested in our split Hopkinson pressure bar.

Open Access This is an open access article distributed under the terms of the Creative Commons Attribution License (http://creativecommons.org/licenses/by/4.0), which permits unrestricted use, distribution, and reproduction in any medium, provided the original work is properly cited.

\section{References}

1. P. Church, W. Huntington-Thresher, C. Herdman, Experimental and simulation analysis of setback in gun launch, in Proc. 19th Int. Symp. on Ballistics, edited by I.R. Crewther (International Ballistics Society, Interlaken, Switzerland, 2001), pp. 223-229 
2. L. Jablansky, Laboratory scale test device to determine sensitivity of explosives to initiation by setback pressure, Picatinny Arsenal Technical Report 2235, 1955

3. L. Jablansky, Factors affecting sensitivity of Composition B to setback. Picatinny Arsenal Technical Report 2433, 1957

4. R.T. Schimmel, G. Weintraub, Effect of base separation and loading density on the setback sensitivity of Composition A3, Picatinny Arsenal Technical Report 4147, 1970

5. O. Listh, Propell. Explos. 3, 36 (1978)

6. T.F. Myers, J. Hershkowitz, The effect of base gaps on setback-shock sensitivities of cast composition B and TNT as determined by the NSWC setback-shock simulator, in Proc. Seventh Symposium (Int.) on Detonation, edited by J.M. Short (Naval Surface Weapons Center, Dahlgren, VA, 1981), pp. 914-923

7. C. Bélanger, G.R. Walker, DREV setback simulator: Design and performance. Centre de Recherches pour la Défense, Valcartier, Canada DREV Report 4274/82, 1982

8. B. Fishburn, Setback safety testing at ARDEC, in Proc. JANNAF Propulsion Systems Hazards Subcommittee Meeting, edited by D.L. Becker (Chemical Propulsion Information Agency, Columbia, MD, 1997), Vol. 1, pp. 219-245

9. J.F. Moxnes, G. Ødegårdstuen, Prediction of deformation of the powder within the nose cap of an MP-projectile during setback and spin, in Proc. 17th Int. Symp. on Ballistics, edited by C. van Niekerk (The South African Ballistics Organisation, Moreleta Park, South Africa, 1998), Vol. 2, pp. 57-66

10. W. Huntington-Thresher, P.D. Church, A. Kosecki, B. Gower, P. Gould, W.G. Proud, D. Chapman, J. Phys. IV France 134, 231 (2006)

11. P.D. Church, R. Townsley, T. Bezance, W.G. Proud, S.G. Grantham, N.K. Bourne, J.C.F. Millett, Int. J. Impact Eng. 32, 80 (2005)

12. J.E. Balzer, C.R. Siviour, S.M. Walley, W.G. Proud, J.E. Field, Proc. R. Soc. Lond. A 460, 781 (2004)

13. J.E. Field, S.M. Walley, W.G. Proud, J.E. Balzer, M.J. Gifford, S.G. Grantham, M.W. Greenaway, C.R. Siviour, Mater. Res. Soc. Symp. Proc. 800, 179 (2004)

14. C.R. Siviour, M.J. Gifford, S.M. Walley, W.G. Proud, J.E. Field, J. Mater. Sci. 39, 1255 (2004)

15. D.M. Williamson, C.R. Siviour, W.G. Proud, S.J.P. Palmer, R. Govier, K. Ellis, P. Blackwell, C. Leppard, J. Phys. D: Appl. Phys. 41, 085404 (2008)

16. D.R. Drodge, D.M. Williamson, S.J.P. Palmer, W.G. Proud, R.K. Govier, J. Phys. D: Appl. Phys. 43, 335403 (2010)

17. S.M. Walley, C.R. Siviour, D.R. Drodge, D.M. Williamson, JOM 62, 31 (2010)

18. R. Chen, L. Cheng, Y. Lin, F. Lu, Int. J. Appl. Mech. 6, 1450039 (2014)

19. J.L. Jordan, J.E. Spowart, M.J. Kendall, B. Woodworth, C.R. Siviour, Philos. Trans. R. Soc. A 372, 20130215 (2014)

20. X.M. Cai, W. Zhang, D.C. Li, W.B. Xie, Optoelectron. Adv. Mater. Rapid Commun. 9, $502(2015)$

21. Z. Hu, H. Luo, S.G. Bardenhagen, C.R. Siviour, R.W. Armstrong, H. Lu, Exp. Mech. 55, 289 (2015)

22. M.J. Kendall, C.R. Siviour, J. Dyn. Behav. Mater. 1, 114 (2015)

23. D.R. Drodge, D.M. Williamson, J. Mater. Sci. 51, 668(2016)

24. S. Ravindran, A. Tessema, A. Kidane, J. Dyn. Behav. Mater. 2, 146 (2016)

25. G.T Gray III, D.J. Idar, W.R. Blumenthal, C.M. Cady, P.D. Peterson, High- and lowstrain rate compression properties of several energetic material composites as a function of strain rate and temperature, in Proc. 11th Int. Detonation Symposium, edited by J.M. Short, J.E. Kennedy (Office of Naval Research, Arlington, VA, 2000), pp. 76-84

26. G.T. Gray III, W.R. Blumenthal, Split-Hopkinson pressure bar testing of soft materials, in ASM Handbook. Mechanical Testing and Evaluation, edited by H. Kuhn, D. Medlin (ASM International, Materials Park, OH, 2000), Vol. 8, pp. 488-496

27. L. Wang, K. Labibes, Z. Azari, G. Pluvinage, Int. J. Impact Eng. 15, 669 (1994)

28. G. Gary, J.R. Klepaczko, H. Zhao, Int. J. Impact Eng. 16, 529 (1995)

29. S. Rao, V.P.W. Shim, S.E. Quah, J. Appl. Polym. Sci. 66, 619 (1997)

30. H. Zhao, G. Gary, J.R. Klepaczko, Int. J. Impact Eng. 19, 319 (1997) 
31. C. Bacon, Exp. Mech. 38, 242 (1998)

32. C. Bacon, Int. J. Impact Eng. 22, 55 (1999)

33. O. Sawas, N.S. Brar, R.A. Brockman, Exp. Mech. 38, 204 (1998)

34. A.S. Yunoshev, V.V. Silvestrov, J. Appl. Mech. Technol. Phys. 42, 558 (2001)

35. D. Casem, W.L. Fourney, P. Chang, Exp. Mech. 43, 420 (2003)

36. Q.L. Liu, G. Subhash, Mech. Mater. 38, 1105 (2006)

37. M. Aleyaasin, J.J. Harrigan, Int. J. Mech. Sci. 52, 754 (2010)

38. B. Ahonsi, J.J. Harrigan, M. Aleyaasin, Int. J. Impact Eng. 45, 39 (2012)

39. R. Curry, T. Cloete, R. Govender, Implementation of viscoelastic Hopkinson bars, EPJ Web Conf. 26, 01044 (2012)

40. C. Bacon, A. Brun, Int. J. Impact Eng. 24, 219 (2000)

41. W. Chen, B. Zhang, M.J. Forrestal, Exp. Mech. 39, 81 (1999)

42. S.J.P. Palmer, D.M. Williamson, W.G. Proud, C. Bauer, AIP Conf. Proc. 955, 849 (2007)

43. W.G. Proud, S.M. Walley, D.M. Williamson, A.L. Collins, J.W. Addiss, Central Eur. J. Energ. Mater. 6, 67 (2009)

44. S.M. Walley, J.E. Field, P.H. Pope, N.A. Safford, Philos. Trans. R. Soc. Lond. A 328, 1 (1989)

45. S.M. Walley, J.E. Field, P.H. Pope, N.A. Safford, J. Phys. III France 1, 18891991

46. A. Trautmann, C.R. Siviour, S.M. Walley, J.E. Field, Int. J. Impact Eng. 31, 523 (2005)

47. G.T. Gray III, Classic split-Hopkinson pressure bar testing, in ASM Handbook. Mechanical Testing and Evaluation, edited by H. Kuhn, D. Medlin (ASM International, Materials Park, OH, 2000), Vol. 8, pp. 462-476

48. A.J. Carmichael, Australian J. Appl. Sci. 15, 289 (1964)

49. C. G'Sell, J.J. Jonas, J. Mater. Sci. 14, 583 (1979)

50. C. G'Sell, J.M. Hiver, A. Dahoun, A. Souahi, J. Mater Sci. 27, 5031 (1992)

51. F. Addiego, A. Dahoun, C. G'Sell, J.-M. Hiver, Polymer 47, 4387 (2006)

52. C. G'Sell, J.M. Hiver, A. Dahoun, Int. J. Solids Struct. 39, 3857 (2002)

53. C.O.R. Abbireddy, C.R.I. Clayton, Granular Matter 17, 427 (2015)

54. M.J. Kendall, C.R. Siviour, Polymer 54, 5058 (2013)

55. D.M. Williamson, Conf. AIP Proc. 2018 (accepted for publication)

56. J.D. Ferry, The transition zone from rubberlike to glasslike consistency, in Viscoelastic Properties of Polymers, 3rd edn. (Wiley, New York, 1980), pp. 321-365

57. N.G. McCrum, B.E. Read, G. Williams, Anelastic Dielectric Effects, in Polymeric Solids (Wiley, London, 1967)

58. M.J. Kendall, C.R. Siviour, Proc. R. Soc. A 470, 20140112 (2014)

59. M.L. Williams, R.F. Landel, J.D. Ferry, J. Am. Chem. Soc. 77, 3701 (1955)

60. J.D. Ferry, Dependence of viscoelastic behavior on temperature and pressure, in Viscoelastic Properties of Polymers, 3rd edn. (Wiley, New York, 1980), pp. 264-320

61. H. Vogel, Phys. Z. 22, 645 (1921)

62. G.S. Fulcher, J. Amer. Ceram. Soc. 8, 339 (1925)

63. G. Tammann, W. Hesse, Z. Anorg. Allgem. Chem. 156, 245 (1926)

64. D. Porter, P.J. Gould, Int. J. Solid Struct. 46, 1981 (2009)

65. J.S. Langer, Rep. Prog. Phys. 77, 042501 (2014)

66. J.A. Nelder, R. Mead, Comput. J. 7, 308 (1965)

67. J.C. Lagarias, J.A. Reeds, M.H. Wright, P.E. Wright, SIAM J. Optimization 9, 112 (1998) 